\title{
Jornalismo ambiental e transparência corporativa: o marketing verde como estratégia de mistificação
}

\author{
Wilson da Costa BUENO ${ }^{1}$ \\ UMESP - Universidade Metodista de São Paulo
}

\begin{abstract}
Resumo
A ausência de uma perspectiva crítica no jornalismo ambiental favorece uma postura equivocada de corporações monopolistas e governos. Eles optam sempre por praticar o marketing verde, desvirtuando conceitos e processos importantes. Este texto descreve as inúmeras contradições da imprensa brasileira que, pressionada pelas empresas e autoridades, permite que interesses não científicos se sobreponham ao interesse público, comprometendo a democracia.
\end{abstract}

Palavras-chave: marketing verde; crime ambiental; transparência corporativa; jornalismo ambiental.

\begin{abstract}
The absence of a critical perspective in environmental journalism promotes the mistaken attitude of corporations and governments. They always opt for practicing green marketing, misrepresenting important concepts and processes. This paper describes the numerous contradictions of Brazilian press. Companies and authorities allow non-scientific interests overlap the public interest, undermining the democracy.
\end{abstract}

Keywords: green marketing; environmental crime; corporative transparency; environmental journalism.

\section{Introdução}

Uma das características mais marcantes da comunicação organizacional de nossos dias é a incidência avassaladora de múltiplos temas controversos, que têm exigido das suas direções (e particularmente das estruturas profissionalizadas de comunicação) disposição e competência para enfrentá-los.

\footnotetext{
1 Jornalista, professor do Programa de Pós Graduação em Comunicação Social da UMESP, com mestrado e doutorado em Comunicação e especialização em Comunicação Rural. Editor de oito portais temáticos em Comunicação/Jornalismo. Diretor da Comtexto Comunicação e Pesquisa e da Mojoara Editorial Ltda.
} 
Evidentemente, a relação das organizações com estes temas depende de sua área de atuação, mas há alguns deles que dizem respeito a todas elas, como a problemática socioambiental (em especial a obrigatoriedade de uma gestão sustentável), a questão ética (a transparência é um dos atributos da organização moderna) e a responsabilidade social (respeito ao consumidor, à comunidade, aos funcionários etc).

Para algumas organizações, alguns temas são absolutamente nevrálgicos, como o respeito à biodiversidade para as empresas que fabricam e comercializam transgênicos; a saúde para a indústria tabagista e farmacêutica; a poluição e a devastação para mineradoras, petrolíferas, empresas de papel e celulose; a segurança para as empresas aéreas etc.

A postura de muitas organizações em momentos de crise evidencia uma disposição recorrente de sonegar informações, falsear a verdade e de burlar os princípios básicos da ética e da transparência.

Embora esta postura injustificável possa ser observada em situações diversas, envolvendo setores cujos produtos impactam dramaticamente a qualidade de vida, como a indústria farmacêutica, a indústria tabagista etc, é importante observar que ela está consolidada na relação das organizações com o meio ambiente, entendido aqui de maneira abrangente, muito além da perspectiva restrita que o identifica apenas com as florestas, as centenas de espécies vegetais ou animais ameaçadas de extinção ou a matança de baleias ou focas.

A prática de muitas organizações demonstra que, apesar do ruído ampliado do debate sobre a importância da sustentabilidade, elas insistem em desvirtuar conceitos e processos, buscando flexibilizá-los para legitimar suas posturas e ações. Fundamentalmente, elas praticam o marketing verde, ou seja apropriam-se de um discurso descolado da realidade, com o objetivo de agregar vantagens competitivas para a sua imagem e reputação.

O marketing verde, ou "green washing", como preferem os autores norteamericanos, representa o conjunto formidável de ações, posturas e estratégias utilizadas por determinadas organizações ou mesmo governos para legitimar um pretenso compromisso com a questão ambiental. $\mathrm{Na}$ verdade, ele se restringe a práticas de comunicação/marketing voltadas para gerar visibilidade institucional ou, no caso de 
empresas, para suas marcas e está dissociado de uma autêntica cultura e gestão ambientais.

Constitui-se, pois, em um processo de mistificação que inicia no campo conceitual, e que se aprofunda nas relações com os "stakeholders" tendo em vista a consolidação de interesses políticos ou empresariais.

A problemática ambiental incorpora noções amplas, como o de desenvolvimento sustentável, sustentabilidade, responsabilidade sócio-ambiental etc, que têm sido desgastadas ao longo do tempo pela ação das organizações, dos governos, com a participação direta de gestores (em particular os de comunicação/marketing) e da própria mídia.

Esta estratégia mistificadora encontra eco na cobertura da mídia por pelo menos dois motivos. Em primeiro lugar, a falta de consciência crítica por parte de veículos e profissionais de imprensa não permite que eles percebam as intenções dos protagonistas do marketing verde, tornando-os reféns ou cúmplices de ações destinadas a mascarar a realidade. O sistema de produção jornalística, cada vez mais acelerado, não favorece a investigação e, muitas vezes, os jornalistas não se dão conta das intenções subjacentes aos fatos e os repercutem sem confrontar a qualidade e a precisão das informações. Em segundo lugar, os veículos mantêm vínculos comerciais importantes com empresas e governos e, quase sempre, se valem da sua contribuição financeira, em forma de anúncios diretos, para garantir a sua sustentabilidade.

Esta situação constrange a mídia e, por extensão os jornalistas, que se vêem obrigados a reproduzir falas e discursos que contribuem para legitimar a prática do marketing verde. Miriam Santini de Abreu (2006), ao analisar dois veículos jornalísticos brasileiros, conclui que eles dissimulam as tensões existentes entre a agressão ao meio ambiente e as intenções comerciais, muitas vezes silenciando vozes que poderiam contribuir para tornar o debate mais concreto e revitalizar conceitos básicos, como o de desenvolvimento sustentável.

\section{Imprensa e sustentabilidade}

A mídia brasileira tem dedicado, ao longo dos últimos anos, espaço e tempo generosos para a temática da sustentabilidade, sobretudo a partir da divulgação dos relatórios do IPCC e da conscientização ampliada do impacto dramático da ação humana sobre o 
clima do planeta . Questões como o aumento da insegurança alimentar, a privatização dos recursos naturais (em especial a da água), o uso das energias renováveis, o desmatamento escandaloso dos biomas (floresta e cerrado em particular) e a destruição da biodiversidade, entre outras, também freqüentam as páginas dos jornais e revistas, os programas de rádio e de televisão, além de espaços privilegiados da web.

A qualidade da cobertura, infelizmente, não tem acompanhado a presença, cada vez mais expressiva, da temática ambiental na imprensa, primando especialmente pelo desvirtuamento dos conceitos, em especial do que contempla a sustentabilidade ou o desenvolvimento sustentável. Ela se acomoda na superficialidade, na ausência de espírito crítico e na intenção deliberada de falsear a verdade, com o objetivo de criar uma imagem positiva para organizações ou empresas que se empenham em moldar um discurso descolado da realidade.

É possível identificar a presença de dois equívocos fundamentais na explicitação do conceito de desenvolvimento sustentável pela mídia brasileira.

O primeiro deles diz respeito ao entendimento que os jornalistas e os veículos, pautados por fontes comprometidas com determinados (e poderosos) interesses, têm do conceito de desenvolvimento, assumido muitas vezes como crescimento econômico, medido pelo aumento do PIB e outros indicadores, todos eles contaminados por uma visão meramente financista. Esta perspectiva restrita acaba privilegiando a vertente econômica em detrimento da sócio-cultural ou política, por exemplo. Não é por outro motivo que se fala em desenvolvimento sustentável dos negócios, da sustentabilidade da economia brasileira etc, um discurso apropriado amplamente por governantes e empresários.

José Eli da Veiga (2007, p.32) recusa aceitar o cálculo atual do PIB como um indicador de desenvolvimento porque, na prática, em virtude do sistema utilizado para quantificálo,

"não existe maneira mais fácil de aumentar o PIB do que abusar da depleção dos recursos humanos ou naturais. Com superexploração do trabalho e/ou da natureza, ele só aumenta, ao mesmo tempo em que diminuem as riquezas verdadeiras".

E dá (2007,p.36) um exemplo ilustrativo deste equívoco contábil:

Exemplos gritantes são os bens militares duráveis e, sobretudo, os armamentos de destruição, que são tratados como investimento produtivo ou como consumo corrente. 
Os técnicos de contas nacionais se defendem como um argumento supostamente neutro: o de que o fornecimento dessas armas deve ser entendido como prestação de serviço para a defesa nacional. Todavia, é óbvio que o caráter destrutivo das operações militares não pode ser visto como um processo de produção, critério norteador das convenções da contabilidade social".

Eli da Veiga (2007, p.41) avança ainda mais em seu argumento contra o cálculo do PIB e sua utilização como parâmetro para medir o desenvolvimento:

O PIB também não considera a acumulação do que tem sido classificado como bens intangíveis: cultura, instituições, confiança entre os agentes ou mesmo direitos humanos. Enquanto uma economia estiver tirando bom proveito mercantil de formas de trabalho escravo e infantil ou de trabalhadores sem quaisquer direitos ou proteção social, seu PIB poderá aumentar mais rapidamente do que noutra em que direitos civis e alguma legislação trabalhista sejam garantidos por meio da fiscalização ou do funcionamento do sistema judiciário. .. Basta pensar nesses fatos civilizadores para entender porque a progressão do PIB da China tem sido tão grandiosa.

O desenvolvimento não se resume a esta perspectiva meramente econômico-financeira, que não apenas empobrece o conceito, mas o desvirtua brutalmente. Desenvolvimento tem a ver com a superação da pobreza e da desigualdade, com a defesa intransigente da pluralidade e da diversidade, com o compromisso com os direitos humanos, com o acesso à educação, à moradia e assim por diante. Crescimento econômico é outra coisa e, em muitos casos, representa um olhar antagônico que, no capitalismo selvagem ou predador, se antepõe à implementação de um efetivo desenvolvimento (o social, o cultural, o das liberdades de pensamento e expressão).

O segundo equívoco implica valer-se do termo (ou melhor do conceito de sustentabilidade) como se ele fosse um adereço qualquer, como um colar ou um brinco que se troca a toda hora para combinar com o resto da roupa. Sustentabilidade, ou sustentável mais apropriadamente, não é apenas um adjetivo, daqueles que se pode trocar por outro qualquer que esteja registrado no velho e útil dicionário do Aurélio.

A sustentabilidade tem a ver com os problemas ambientais, mas não se esgota neles, muito pelo contrário. $\mathrm{Na}$ verdade, quem age dessa forma assume explicitamente que o meio ambiente é algo deslocado da economia, da cultura, da sociedade, algo que se possa dominar, como as teorias neoliberais de desenvolvimento continuam apregoando. Um modelo comprometido com o consumo desenfreado e com todo tipo de insustentabilidade explícita, como a geração estúpida de lixo (especialmente o eletrônico em nossos dias), o uso indiscriminado de agrotóxicos e a ameaça à diversidade não abrem espaço para uma perspectiva efetivamente sustentável. 
A sustentabilidade se manifesta na proteção do conhecimento tradicional e da diversidade de línguas (em particular, as utilizadas por indígenas e minorias em geral); no repúdio ao monopólio das sementes, na resistência à ideologia desenvolvimentista que respalda uma perspectiva de desenvolvimento centrada no curto prazo e que faz a apologia do progresso técnico; na valorização do pluralismo de idéias e de opiniões contrariamente à tentativa de impor uma mentalidade transgênica e assim por diante.

Vandana Shiva (2003) cunhou, com felicidade, a expressão "monoculturas da mente" para caracterizar esta mentalidade transgênica, avessa ao pluralismo, que promove, segundo ela, a destruição dos sistemas locais de saber. Admite que a ideologia que respalda o processo de globalização, comprometida com o pensamento científico ocidental, tem a ver com "um status epistemológico", identificada com o positivismo, o verificacionismo e o falsificacionismo", ou seja, fundada no

\begin{abstract}
"pressuposto de que, ao contrário das crenças tradicionais, das crenças locais do mundo, que são construídas socialmente, pensava-se que o saber científico moderno era determinado sem a mediação social". Por isso, explica ele, "quando o saber local aparece de fato no campo da visão globalizadora, fazem com que desapareça negandolhe o status de um saber sistemático e atribuindo-lhe os adjetivos de 'primitivo' e 'anticientifico'. Entretanto, os prefixos 'científico' para os sistemas modernos e 'anticientífico' para os sistemas tradicionais de saber têm pouca relação com o saber e muita com o poder" (p.23).
\end{abstract}

A sustentabilidade, resgatada em seu conceito mais amplo, não se limita ao esgotamento ou preservação dos recursos naturais, mas tangencia também outras áreas e é, com esta amplitude que precisa ser trabalhada pela cobertura jornalística.

Neste sentido, soa como absolutamente equivocada a falta de visão crítica de determinados veículos que distorcem de tal modo o conceito que tornam possível considerar empresas ou setores, por definição insustentáveis, como "amigos do meio ambiente". Este foi o caso de reportagem recente de uma revista de grande circulação Época - que, ao estabelecer um ranking de empresas sustentáveis, incluiu, dentre elas, a Souza Cruz, maior indústria tabagista no Brasil. Como pode uma empresa que está definitivamente empenhada no aumento do consumo do tabaco, responsável por milhões de mortes por ano no mundo inteiro, candidatar-se como sustentável, se ela não "sustenta" ao menos a vida de seus consumidores? Como separar o conceito de sustentabilidade do de qualidade de vida ou até mesmo do de existência de vida? 
A exemplo de outros conceitos, como o de responsabilidade social (aliás, modernamente inserido no de sustentabilidade ou de gestão socioambiental), o conceito de sustentabilidade tem sido apropriado indevidamente e utilizado como ícone para ações e estratégias de manipulação da opinião pública.

A imprensa, que não está atenta para identificar e denunciar estes desvios, acaba incorporando falas e discursos que estão migrando, cada vez mais, das corporações para os governos e para o próprio Congresso Nacional.

O desenvolvimento sustentável não se mede pelo $\mathrm{PIB}$, nem pela exportação de commodities agrícolas ou minerais; não se aplica a segmentos econômicos que predam a natureza e que insistem em praticar o discurso do "marketing verde".

A imprensa brasileira continua praticando um conceito "sui generis" de sustentabilidade porque a vislumbra a partir de um modelo contaminado por interesses escusos e que se caracteriza pela incompletude e pela imprecisão.

Miriam Santini de Abreu (2006, p.15) é contundente na avaliação da cobertura jornalística do meio ambiente e agrega ao lobby dos protagonistas (empresas, governos) algumas características inerentes ao próprio sistema de produção jornalística:

“A 'doutorização' da linguagem e a falsidade dos discursos globais sobre a natureza emsombrecem o entendimento', impede que assome uma 'comunicação imaginosa', 'emocionada', 'veraz e de baixo para cima', como sonhava Santos (a autora referia-se a Milton Santos). Essa comunicação também é impedida pelo mito da objetividade e da isenção no jornalismo, baseado na crença impostora de que o fato tem que virar notícia sendo o jornalista neutro, impessoal, imparcial, isento e objetivo."

Ela (2006,p.15-6) chama a atenção para o fato de que as vozes do povo, apresentado como algo à parte da sociedade" estão silenciadas na cobertura ambiental e para uma "visão atomizada, compartimentada" que se manifesta no jornalismo em função da "sua divisão em especializações e a segmentação dos veículos em razão dos públicos, das faixas horárias, dos interesses do onipresente mercado. O 'jornalismo ambiental' é fruto dessa repartição interesseira do jornalismo".

Há espaços de divulgação ou temas ambientais em que esse discurso hegemônico comprometido com a disseminação das vantagens de determinados insumos (toda a gama dos chamados "cidas" - pesticidas, herbicidas, inseticidas,além do mais nobre deles, as sementes) se manifesta. É o caso dos agrotóxicos e dos transgênicos, em que o 
cientificismo e a competência tecnológica tendem a legitimar danos importantes ao meio ambiente e o discurso grandiloqüente, mas enganoso, das grandes corporações.

\section{Os agrotóxicos e a síndrome da monofonte}

O Censo Agropecuário (IBGE) foi implacável com as empresas agroquímicas e empresários rurais ( e indiretamente com o Governo) ao trazer à luz uma verdade indiscutível: parcela significativa dos agricultores não recebe assistência técnica ou conta com auxílio de equipamentos adequados de proteção individual e se expõe perigosamente aos agrotóxicos (que são veneno e não remedinho de planta!).

Muitos são os motivos que explicam este cenário desfavorável. Em primeiro lugar, a baixa escolaridade dos trabalhadores rurais dificulta o acesso e o entendimento das informações sobre os agrotóxicos e seus riscos. Em segundo lugar, a orientação técnica não é prestada para a maioria dos estabelecimentos que usam agrotóxicos, falhando nesse processo tanto as agroquímicas como a assistência oficial, notadamente para propriedades de pequeno porte. Finalmente, a propaganda abusiva destes produtos (que subsidia boa parte dos veículos e programas voltadas para o meio rural) e o interesse em aumentar o consumo a qualquer custo acabam incentivando a aplicação, com prejuízos aos que estão no campo mas também aos que consomem os produtos na cidade.

O censo do IBGE evidenciou o aumento do número de propriedades que utilizam agrotóxicos (mais de 50\% de 1996 a 2006), exatamente em estabelecimentos de pequeno porte onde a falta de assistência e a baixa escolaridade são mais percebidas.

A ANVISA busca coibir abusos na aplicação dos agrotóxicos, mas tem enfrentado o lobby formidável das agroquímicas que se empenham para incentivar o consumo, com o discurso hipócrita do aumento da produtividade da lavoura e do controle efetivo das pragas.

É verdade que os agrotóxicos podem ajudar no combate aos organismos que predam as culturas vegetais mas é sabido também, que simultaneamente, provocam o surgimento de outras. Os agrotóxicos afrontam o meio ambiente, poluindo a água, o solo, o ar e penalizando, de maneira dramática, a saúde dos que os manipulam, tomam contato com eles ou se servem dos alimentos por eles contaminados. 
Recentemente, dois episódios trouxeram à tona a realidade do setor de agrotóxicos no Brasil, envolvendo duas grandes agroquímicas mundiais.

Os comunicados da ANVISA e do IBAMA referentes à irregularidades, respectivamente, nos produtos da Bayer e da Basf, ilustram este fato.

O relato da ANVISA é esclarecedor (1):

“A Agência Nacional de Vigilância Sanitária interditou (dia 24 de setembro de 2009), 1 milhão de litros de agrotóxicos adulterados, em Belford Roxo (RJ). A fiscalização, realizada pela Agência com apoio da Polícia Federal, ao longo de toda semana passada na empresa Bayer, de origem alemã, identificou a produção de agrotóxicos com formulação adulterada, sem autorização dos órgãos competentes.

No total foram encontradas irregularidades em 12 agrotóxicos. O caso mais grave, identificado pela Agência, foi a importação do ingrediente ativo do agrotóxico Procloraz e a produção do agrotóxico comercial Sportak 450 EC, sem controle obrigatório de impurezas toxicologicamente relevantes. A falta desse controle pode causar câncer nos trabalhadores expostos ao agrotóxico e na população que ingere alimentos contaminados com tais produtos".

O comunicado da ANVISA informa também que a interdição é válida por 90 dias e lembra que, no começo deste ano, a Bayer teve o registro do agrotóxico Evidence (utilizado nas culturas de cana de açúcar e fumo) cancelado. Isso ocorreu porque era produzido com adulteração na fórmula.

Já o IBAMA (2) informa:

"Por produção e comercialização de agrotóxicos em desconformidade com a licença obtida, duas filiais da Basf SA. foram autuadas pelo IBAMA. A operação apreendeu 99 sacos de $15 \mathrm{Kg}$ do agrotóxico Granutox $150 \mathrm{G}$, armazenados na empresa em Ibiporã/PR...

O ingrediente ativo Forato, utilizado no Granutox 150G, foi um dos selecionados para ser reavaliado devido a indícios de danos ambientais constatados por meio de restrições de uso, banimentos e cancelamentos em outros países. Uma das reavaliações do ingrediente ativo foi conduzida pela Agência de Proteção Ambiental dos Estados Unidos - EPA. A agência norteamericana demonstrou preocupação em relação às características ecotoxicológicas deste ingrediente ativo. Os riscos para aves e peixes foram considerados elevados... O Forato também se encontra na lista dos ingredientes ativos a serem reavaliados pela ANVISA devido a indícios de danos à saúde humana".

Como se pode depreender das notícias acima, a falta de responsabilidade de empresas e empresários rurais, que deveriam oferecer os equipamentos de proteção para os seus trabalhadores e minimizar os danos ao meio ambiente e à saúde, é evidente . 
As agroquímicas costumam ter trânsito livre nos cursos de ciências agronômicas, com ações desencadeadas para seduzir os futuros profissionais, patrocinam eventos em agropecuária e investem pesado nas mídias especializadas da área. Ou seja: há um esforço importante no sentido de criar uma imagem positiva para o veneno, utilizado indiscriminadamente, com riscos à saúde e ao meio ambiente.

A imprensa deveria estar mais vigilante em relação ao material que provém do Setor (que insiste em utilizar a expressão defensivos agrícolas como forma de mascarar o seu teor tóxico), buscando sempre contrapor fontes que fazem a apologia dos agrotóxicos com outras que sistematicamente têm denunciado os problemas por ele causados. Uma delas, de absoluta competência, é a Fiocruz, que recorrentemente desenvolve pesquisas para confirmar o impacto dos agrotóxicos na saúde humana. Elas revelam quase sempre estatísticas dramáticas de contaminação no ser humano (leite materno, sangue etc) e nos produtos servidos à população.

Reportagem da Folha de S. Paulo (CORREA, 2011, p.C1) indica que

\begin{abstract}
"quase um terço dos vegetais mais consumidos pelos brasileiros apresenta resíduos de agrotóxicos em níveis inaceitáveis. Das amostras de alimentos analisadas pela agência, referentes ao ano de 2010, 28\% apresentaram ou limites acima do recomendável ou substâncias não aprovadas para o produto - um agrotóxico recomendado para o cultivo de eucalipto usado numa lavoura de tomate, por exemplo."
\end{abstract}

A imprensa reproduz sem questionamento materiais e ações provenientes das fabricantes de agrotóxicos (releases, coletivas de imprensa, folhetos etc) sem se dar conta de que há grandes interesses em jogo. Não desconfia de fontes aparentemente técnico-científicas que se manifestam a seu favor porque setores poderosos (movimentam bilhões de dólares anualmente) como agroquímica, biotecnologia, e a indústria da saúde em geral etc costumam valer-se deles para influenciar a opinião pública.

Em geral, a cobertura de setores como o da biotecnologia e da agroquímica tem-se limitado a fontes oficiais, muitas vezes porta-vozes de empresas do setor, como diretores de marketing ou de pesquisa $\&$ desenvolvimento, e quase sempre publicada nos cadernos de economia e negócios. Ela padece da "síndrome da monofonte", ou seja, está respalda em fonte única, exclusiva, comprometida com os interesses de organizações ou entidades empresariais, sem qualquer contraponto ou contestação. 
Este desvio de conduta jornalística que deveria, para temas controversos como esses, adotar o pluralismo de fontes, contrapondo vozes comprometidas com o meio ambiente e a saúde com aquelas que defendem os interesses comerciais, acaba penalizando o processo de conscientização dos cidadãos em direção a uma cultura e a um consumo sustentáveis.

\section{A apologia da redução do desmatamento}

O marketing verde manifesta-se também na adesão acrítica dos veículos jornalísticos aos anúncios governamentais sobre redução do desmatamento na Amazônia, o que evidencia, de imediato, ausência de uma perspectiva temporal e comprometida com o futuro.

Ignorando a incontestável realidade de que a floresta é um bem finito, autoridades, jornalistas e a mídia de maneira geral admitem ser absolutamente positiva a notícia de que, por exemplo, entre agosto de 2010 e julho de 2011, os satélites do INPE - Instituto Nacional de Pesquisas Espaciais registraram o corte de $6.280 \mathrm{Km} 2$ de matas, o equivalente a quatro vezes o tamanho da cidade de São Paulo.

Analisada a partir de uma perspectiva histórica, temporal, o desmatamento continua elevado e ameaça, a médio e longo prazos, o futuro da floresta amazônica, ainda que, pontualmente, possa ter atingido, como insiste o Governo, na menor taxa anual de desmatamento desde 1988. Os níveis de desmatamento oscilam com freqüência e é razoável suspeitar (embora veículos e jornalistas pareçam não perceber a intenção do anúncio neste momento) que este "recorde" esteja sendo festejado ao mesmo tempo em que se realiza, em Durban, na África do Sul, a 17 . Conferência do Clima (COP-17), onde políticas públicas brasileiras estejam sendo contestadas, em particular em função da proposta, já aprovada pelo Senado, do Novo Código Florestal.

A mídia que, como acentuava Mirian Santini de Abreu já citada neste texto, se caracteriza pela cobertura fragmentada da questão ambiental, com raras exceções, não consegue estabelecer estas relações e assume uma posição oficialesca saudando dados pontuais sem qualquer proposta de contextualização.

Especialistas admitem que uma área equivalente a dois Estados de São Paulo pode ficar desprotegida na Amazônia com as alterações propostas para o novo Código Florestal. Comungam desta tese o próprio secretário nacional de Mudanças Climáticas, Eduardo 
Assad, pesquisadores da Embrapa, como Carlos Padovani, preocupado com a situação específica do Pantanal, e o vice-presidente da SBPC - Sociedade Brasileira para o Progresso da Ciência, Ennio Candotti, que tem se manifestado sobretudo pelo impacto do novo Código nas áreas inundáveis sazonalmente.

A redução pontual do desmatamento na Amazônia não significa, muito pelo contrário, que a floresta não esteja sob séria ameaça, mesmo porque os próprios dados divulgados pelo INPE mostram que há crescimento significativo do desmate em alguns Estados, como Mato Grosso e Rondônia.

É preciso ainda ter em vista o impacto presente futuro a ser causado pela construção de usinas hidrelétricas, como a de Santo Antônio e Jirau, no Rio Madeira, e a de Belo Monte, e mesmo o fato, não ignorado, de que o monitoramento do INPE não identifica necessariamente o desmate em áreas pequenas, o que é muito comum na região.

A falta de transparência e a manipulação de dados representam estratégias utilizadas por empresas e governos para encobrir a realidade e constituem atributos indissociáveis da prática do marketing verde.

\section{O caso emblemático da Chevron}

Um exemplo dramático da falta de transparência e da irresponsabilidade socioambiental pode ser percebida no acidente provocado pela Chevron na Bacia de Campos em novembro de 2011, amplamente coberto pela mídia.

O vazamento de óleo iniciou-se no dia 7 de novembro, mas a empresa apenas só notificou as autoridades dois dias depois e talvez tivesse demorado mais ainda para reconhecer o problema, se funcionários da Petrobras que sobrevoavam a área em um helicóptero não tivessem percebido a mancha no mar.

Recorrentemente, a Chevron buscou mascarar o problema e a sua responsabilidade pelo crime ambiental. Em primeiro lugar, divulgou dados falsos sobre a quantidade de óleo vazado, tentando minimizar o acidente, o que impediu uma ação mais rápida e enérgica para estancar o vazamento. Em segundo lugar, atribuiu o dano a uma rachadura no leito do oceano, sem confessar que a perfuração por ela promovida havia provocado o problema. Em terceiro lugar, sonegou fotos que evidenciavam a real dimensão do acidente e editou imagens com o objetivo explícito de enganar os órgãos de fiscalização. 
Em quarto lugar, ficou patente que ela não tinha um plano de emergência que permitisse estancar vazamentos, caso eles ocorressem. Finalmente, como seria descoberto duas semanas mais tarde, a Chevron produziu, sem conhecimento das autoridades, um gás tóxico (gás sulfídrico) na plataforma de produção de Frade, na bacia de Campos, comprometendo a saúde dos trabalhadores.

Embora a ANP - Agência Nacional de Petróleo, o IBAMA e o Governo do Rio de Janeiro tenham imposto multa à empresa pelos danos causados, é forçoso reconhecer que, no Brasil, elas costumam não ser pagas e que há artifícios jurídicos que permitem recursos repetidos para impedir a punição imediata.

Um mês após o acidente, a Chevron continuava postergando o depoimento de seu presidente no Brasil, Georg Buck, certamente convicta de que havia pouco a declarar em favor da empresa e preocupado com o seu desempenho midiático, o que já havia sido constatado durante a audiência na Câmara dos Deputados quinze dias após o acidente.

A imprensa brasileira não poupou a Chevron pelo crime ambiental, mas esteve sobretudo atenta à falta de transparência da empresa. A revista Carta Capital fez do acidente a sua matéria de capa do dia 30 de novembro, com o seguinte título: "Chevron: trapaças e mentiras" e o seguinte complemento: "quanto mais tenta explicar, mais a Chevron se enrola na história do vazamento no litoral do Rio de Janeiro". A revista Isto é Dinheiro, na mesma data, também fez do crime da Chevron a sua reportagem de capa, com o título "O caso Chevron”, trazendo em destaque o rosto do seu presidente, acompanhado de palavras como mentiras, negligência, imprudência e crime ambiental”.

Os editoriais dos principais veículos do País aumentaram também o tom contra a empresa e também não deixaram impunes os órgãos de fiscalização e controle pelo ocorrido. A crítica sobre a falta de transparência foi a tônica, como era de se esperar.

O editorial do Estado de S. Paulo, de 23 de novembro, com o título "O vazamento de óleo", cobrava transparência da empresa (3):

Depois do vazamento de milhares de litros de óleo no Campo do Frade, na Bacia de Campos, da responsabilidade da Chevron, torna-se imperativo dispor de um Plano de Contingência para casos de acidentes desse tipo, reclamado há 11 anos por ambientalistas. E para isso o governo deve, em primeiro lugar, exigir absoluta 
transparência das atividades das companhias que extraem petróleo na área, sejam concessionárias, seja a própria Petrobras. Detectado o vazamento no dia 8 deste mês, a $120 \mathrm{Km}$ da costa do Estado do Rio de Janeiro, a Chevron demorou para se pronunciar e, quando o fez, atribuiu a mancha de óleo no mar a uma falha geológica. A Agência Nacional de Petróleo (ANP) e o IBAMA tampouco mostraram apego pela transparência, o que levou a protestos de ambientalistas".

É importante, no entanto, destacar que, apesar da ação correta da mídia após o crime ambiental estar consumado, os veículos demoram muito para perceber a amplitude do acidente e para situá-lo em sua verdadeira dimensão. Na verdade, no primeiro momento, como tem sido habitual, ficaram reféns de fontes oficiais e mesmo da própria Chevron, o que contribuiu para que a cobertura específica e com tons reais aparecesse apenas muito tempo após o vazamento do óleo.

A própria ombudsman da Folha de S. Paulo, Suzana Singer, em comentário publicado no dia 27 de novembro de 2011, chamava a atenção para o fato, com o título ilustrativo da sua coluna " O óleo subiu...e a gente não viu". (4) Nela, afirmava que "a chamada 'grande imprensa' demorou a entender a gravidade do que estava acontecendo, reproduziu passivamente a versão oficial e não fez apuração própria” e, com humor e ironia, acrescentava:

"Só com a entrada da Polícia Federal no caso, a Folha e seus concorrentes começaram a se mexer de fato. O conselho jornalístico 'follow the money' virou no Brasil, por preguiça, 'follow the police'. Finalmente, ela constatou: " O caso Chevron mostra que faltam jornalistas especializados em petróleo, o que é grave num país que tem uma estatal do tamanho da Petrobras e que pretende ser uma potência da área com a exploração do pré-sal".

Nesse sentido, é fundamental assinalar que blogueiros, ONGs internacionais e até o Sindicato dos petroleiros foram mais competentes, reconhecendo a importância do acidente desde o primeiro momento e chamando a atenção para a inconsistência das versões oficiais.

Pode-se descobrir, durante a divulgação do crime ambiental da Chevron, que a Petrobras detém participação no empreendimento (30\% da sociedade), que a Chevron já foi multada no Equador por dano semelhante, o que não havia sido mencionado pela mídia que, aparentemente, ignorou o fato. Por isso, é interessante observar que o jornal O Estado de S. Paulo, em seu editorial aqui mencionado, diferentemente do que tem sido a sua conduta, recorreu a ambientalistas para tecer críticas à Chevron e aos órgãos de governo. $\mathrm{Na}$ verdade, elas eram as fontes fundamentais nesse episódio, mas integram, muitas vezes, aquelas vozes silenciadas de que fala Mirian Santini de Abreu 
em seu trabalho sobre a farsa do discurso jornalístico sobre desenvolvimento sustentável.

A divulgação da questão ambiental padece de uma série de síndromes e não está atenta à ação de lobbies, de fontes comprometidas, da enervante miopia da mídia que privilegia a espetacularização da notícia em detrimento do necessário espírito investigativo.

A pauta ambiental exige atenção redobrada dos jornalistas porque, nessa área, há, sistematicamente, convergência de múltiplos interesses que se empenham em falsear a verdade, em sonegar as informações e abrir mão da transparência e da ética na comunicação:

A pauta ambiental não se esgota na contemplação da superfície (há sempre razões encobertas) e geralmente o equívoco está em buscar soluções sem que se possa (ou se queira) vislumbrar o quadro completo. A pauta ambiental é sempre complexa porque não se reduz a uma instância meramente técnica ou científica, mas agrega uma perspectiva econômica, uma vontade (ou falta de vontade) política, uma componente sócio-cultural e assim por diante. $\mathrm{O}$ erro está sempre em não perceber as conexões intrincadas entre meio ambiente, economia, cultura, política e sociedade, em reduzir, por ingenuidade ou falta de conhecimento, a pauta a uma instância particular, simplista, num reducionismo que favorece os grandes interesses. (BUENO, 2007, p.38-9)

O marketing verde legitima a falta de transparência e precisa ser combatido com o olhar atento, o conhecimento dos conceitos e processos, a averiguação cuidadosa do compromisso das fontes e o desvelamento das intenções de governos e corporações.

\section{Notas}

1) Ver a notícia completa em

http://www.anvisa.gov.br/divulga/noticias/2009/280909.htm, acessada em 07/12/2011.

2) A reportagem está publicada no portal do órgão

http://www.ibama.gov.br/noticias-2009/ibama-multa-basf-por-agrotoxico-irregular $\quad$ e foi acessada em 06/12/2011.

3) O Estado de S. Paulo. O vazamento de óleo. São Paulo, 23/11/2011, p. A3.

4) SINGER, Suzana. O óleo subiu...e a gente não viu. Folha de S. Paulo. São Paulo, 27/11/2011, p. A8.

\section{Referências}

ABREU, Míriam Santini de. Quando a palavra sustenta a farsa: o discurso jornalístico do desenvolvimento sustentável. Florianópolis:Editora da UFSC, 2006. 
BUENO, Wilson da Costa. Comunicação, jornalismo e meio ambiente: teoria e pesquisa. São Paulo:Mojoara Editorial, 2007.

ELKINGTON, John. Sustentabilidade, canibais com garfo e faca. São Paulo: M.Books do Brasil, 2011.

GUEVARA, Arnoldo José de Hoyos; ROSINI, Alessandro Marco; SILVA, José Ultemar da; RODRIGUES, Mônica Cairrão (org). Consciência e desenvolvimento sustentável nas organizações. Rio de Janeiro:Campus,2009.

LAVILLE, Elisabeth. A empresa verde. São Paulo:Õte, 2009.

LOUREIRO, Carlos Frederico B. Loureiro (org). A questão ambiental no pensamento crítico. Rio de Janeiro:Quartet, 2007.

MAKOWER, Joel. A economia verde. São Paulo: Gente, 2009.

PORTO-GONÇALVES, Carlos Walter. O desafio ambiental. Rio de Janeiro:Record, 2004.

SACHS, Ignacy. Rumo à ecossocioeconomia: teoria e prática do desenvolvimento. São Paulo: Cortez Editora, 2007.

SATO, Michele; CARVALHO, Isabel. Educação ambiental: pesquisas e desafios. Porto Alegre:Artmed,2005.

SAVITZ, Andrew W. A empresa sustentável. Rio de Janeiro:Elsevier,2007.

SHIVA, Vandana. Monoculturas da mente. São Paulo:Gaia, 2003.

VEIGA, José Eli. A emergência socioambiental. São Paulo:Editora SENAC, 2007. 